\title{
THE SMALLEST HARMONIC INDEX OF TREES WITH GIVEN MAXIMUM DEGREE
}

\author{
REZA RASI \\ AND \\ Seyed Mahmoud Sheikholeslami \\ Department of Mathematics \\ Azarbaijan Shahid Madani University \\ Tabriz, I.R. Iran \\ e-mail: \{r.rasi;s.m.sheikholeslami\}@azaruniv.edu
}

\begin{abstract}
The harmonic index of a graph $G$, denoted by $H(G)$, is defined as the sum of weights $2 /[d(u)+d(v)]$ over all edges $u v$ of $G$, where $d(u)$ denotes the degree of a vertex $u$. In this paper we establish a lower bound on the harmonic index of a tree $T$.
\end{abstract}

Keywords: harmonic index, trees.

2010 Mathematics Subject Classification: 05C12, 92E10.

\section{REFERENCES}

[1] H. Deng, S. Balachandran, S.K. Ayyaswamy and Y.B. Venkatakrishnan, On the harmonic index and the chromatic number of a graph, Discrete Appl. Math. 161 (2013) 2740-2744.

doi:10.1016/j.dam.2013.04.003

[2] H. Deng, S. Balachandran, S.K. Ayyaswamy and V.B. Venkatakrishnan, On harmonic indices of trees, unicyclic graphs and bicyclic graphs, Ars Combin. 130 (2017) 239-248.

[3] S. Fajtlowicz, On conjectures of Graffiti-II, Congr. Numer. 60 (1987) 187-197.

[4] B. Furtula, I. Gutman and M. Dehmer, On structure-sensitivity of degree-based topological indices, Appl. Math. Comput. 219 (2013) 8973-8978.

doi:10.1016/j.amc.2013.03.072 
[5] O. Favaron, M. Mahio and J.F. Sacle, Some eigenvalue properties in graphs (Conjectures of Graffiti-II), Discrete Math. 111 (1993) 197-220. doi:10.1016/0012-365X(93)90156-N

[6] I. Gutman, Degree-based topological indices, Croat. Chem. Acta 86 (2013) 351-361. doi: $10.5562 /$ cca2294

[7] I. Gutman and N. Trinajstić, Graph theory and molecular orbitals, Total-electron energy of alternant hydrocarbons, Chem. Phys. Lett. 17 (1972) 535-538. doi:10.1016/0009-2614(72)85099-1

[8] I. Gutman, L. Zhong and K. Xu, Relating ABC and harmonic indices, J. Serb. Chem. Soc. 79 (2014) 557-563. doi:10.2298/JSC130930001G

[9] Y. Hu and X. Zhou, On the harmonic index of the unicyclic and bicyclic graphs, WSEAS Trans. Math. 12 (2013) 716-726.

[10] A. Ilic, Note on the harmonic index of a graph, Appl. Math. Lett. 25 (2012) 561566. doi:10.1016/j.aml.2011.09.059

[11] M.A. Iranmanesh and M. Saheli, On the harmonic index and harmonic polynomial of caterpillars with diameter four, Iranian J. Math. Chem. 6 (2015) 41-49.

[12] J. Li and W.C. Shiu, The harmonic index of a graph, Rocky Mountain J. Math. 44 (2014) 1607-1620. doi:0.1216/RMJ-2014-44-5-1607

[13] J. Liu, On harmonic index and diameter of graphs, J. Appl. Math. Phys. 1 (2013) $5-6$. doi:10.4236/jamp.2013.13002

[14] J. Liu, On the harmonic index of triangle-free graphs, Appl. Math. 4 (2013) 12041206. doi:10.4236/am.2013.48161

[15] J. Liu, Harmonic index of dense graphs, Ars Combin. 120 (2015) 293-304.

[16] J. Liu and Q. Zhang, Remarks on harmonic index of graphs, Util. Math. 88 (2012) 281-285.

[17] J.B. Lv, J. Li and W.C. Shiu, The harmonic index of unicyclic graphs with given matching number, Kragujevac J. Math. 38 (2014) 173-183. doi:doi.org/10.5937/KgJMath1401173J

[18] S. Liu and J. Liu, Some properties on the harmonic index of molecular trees, ISRN Appl. Math. (2014) 1-8.

[19] R. Rasi, S.M. Sheikholeslami and I. Gutman, On harmonic index of trees, MATCH Commun. Math. Comput. Chem. 78 (2017) 405-416.

[20] R.Wu, Z. Tang and H. Deng, A lower bound for the harmonic index of a graph with minimum degree at least two, Filomat 27 (2013) 51-55. doi:10.2298/FIL1301051W 
[21] R. Wu, Z. Tang and H. Deng, On the harmonic index and the girth of a graph, Util. Math. 91 (2013) 65-69.

[22] X. Xu, Relationships between harmonic index and other topological indices, Appl. Math. Sci. 6 (2012) 2013-2018.

[23] L. Yang and H. Hua, The harmonic index of general graphs, nanocones and triangular benzenoid graphs, Optoelectron. Adv. Mater. - Rapid Commun. 6 (2012) 660-663.

[24] L. Zhong, The harmonic index for graphs, Appl. Math. Lett. 25 (2012) 561-566. doi:10.1016/j.aml.2011.09.059

[25] L. Zhong, The harmonic index of unicyclic graphs, Ars Combin. 104 (2012) 261-269.

[26] L. Zhong, The harmonic index for unicyclic and bicyclic graphs with given matching number, Miskolc Math. Notes 16 (2015) 587-605.

[27] L. Zhong and Q. Cui, The harmonic index for unicyclic graphs with given girth, Filomat 29 (2015) 673-686. doi:10.2298/FIL1504673Z

[28] L. Zhong and K. Xu, The harmonic index for bicyclic graphs, Util. Math. 90 (2013) $23-32$.

[29] L. Zhong and K. Xu, Inequalities between vertex-degree-based topological indices, MATCH Commun. Math. Comput. Chem. 71 (2014) 627-642.

[30] Y. Zhu, R. Chang and X. Wei, The harmonic index on bicyclic graphs, Ars Combin. 110 (2013) 97-104.

[31] Y. Zhu and R. Chang, On the harmonic index of bicyclic conjugated molecular graphs, Filomat 28 (2014) 421-428. doi:10.2298/FIL1402421Z

[32] Y. Zhu and R. Chang, Minimum harmonic index of trees and unicyclic graphs with given number of pendant vertices and diameter, Util. Math. 93 (2014) 345-374.

[33] A. Zolfi, A.R. Ashrafi and S. Moradi, The top ten values of harmonic index in chemical trees, Kragujevac J. Sci. 37 (2015) 91-98.

Received 2 September 2016

Revised 9 January 2017

Accepted 9 January 2017 